\title{
COVID-19: REPLICATION INHIBITORS AS PROMISING THERAPY FOR SYMPTOMATIC PATIENTS
}

\author{
Haghamad Allzain ${ }^{1} \bowtie$ (iD, Yassir Hamadalnil 2 (D) \\ ${ }^{1}$ Assistant Professor in the Department of Biochemistry, Faculty of Medicine, Shendi University, Sudan. \\ ${ }^{2}$ Department of Clinical Microbiology, Faculty of Medicine, Nile University, Khartoum, Sudan.
}

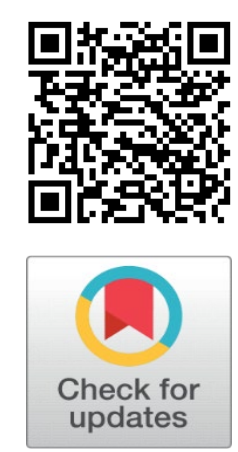

Received 18 October 2021

Accepted 4 November 2021

Published 30 November 2021

\section{CorrespondingAuthor}

Haghamad Allzain,

hajamadbulla@yahoo.com.

DOI

10.29121/granthaalayah.v9.i11.2021 .4337

Funding: This research received no specific grant from any funding agency in the public, commercial, or not-for-profit sectors.

Copyright: (C) 2021 The Author(s). This is an open access article distributed under the terms of the Creative Commons Attribution License, which permits unrestricted use, distribution, and reproduction in any medium, provided the original author and source are credited.

\section{ABSTRACT}

COVID-19 is unprecedented pandemic threading the mankind existence in the recent time, with globally reported $(256,966,237)$ confirmed cases, including $(5,151,643)$ death, as of 22 of November 2021WHO (2020). The COVID-19 vaccine doses administered globally were $(7,408,870,760)$ doses as of 22 of November 2021 WHO (2020).

Strategy to face this serious threat include prevention of getting infection and rational treatment of symptomatic infected ones. Treatment can adopt one or all of the three strategies; prohibiting the virus from entry into the human cells, halt replication of the virus inside the human cells, and neutralizing the inflammatory and other effects of the virus pathogencity.

Replication inhibitors are important tool in the tools box against COVID-19, however they are not substitute for vaccination against COVID-19 and other adopted preventive measurements. Still prevention is the best medicine for any disease.

The aim of this review is to further explore the replication inhibitors as emerging tools for treatment of symptomatic cases of COVID-19. Many encouraging results have emerged from recent clinical trials. This may help to bridge the gap in existence knowledge and stimulate further discussion to enhance conducting more clinical trials for the treatment of COVID-19 and repurpose already existing other viral replicating indictors for treatment of COVID-19. Remdesivir, Molnupiravir and Paxlovid are promising viral replicating inhibitors drugs for treatment of symptomatic COVID-19 patients. Since Molnupiravir and Paxlovid are given orally as five days short course, are significantly of great value for low-income countries.

Keywords: COVID-19, Coronavirus, Remdesivir, Molnupiravir, Paxlovid

\section{INTRODUCTION}

Coronaviruses belong to the Coronaviridae family in the order Nidovirales, it possesses a crown-like spikes on the outer surface of the virus; so, it was named Boopathi et al. (2020), Coronaviruses size is (65-125 nm) in diameter and contain a positive sense, single-stranded RNA as a nucleic material with size ranging from 26 to $32 \mathrm{kbs}$ in length Schoeman and Fielding (2019). The subgroups of coronaviruses family are alpha $(\alpha)$, beta $(\beta)$, gamma $(\gamma)$ and delta $(\delta)$ coronavirus. Beta. These viruses were thought to infect only animals until the world witnessed a severe acute respiratory syndrome (SARS) outbreak caused by SARS-CoV, 2002 in Guangdong, China. Another pathogenic coronavirus, known as Middle East respiratory syndrome coronavirus (MERS-CoV) caused an endemic in Middle Eastern Countries. a decade later Harapan and Itoh. (2020) 
Khan et al. (2020). However, beta-coronaviruses are clinically important group because they comprise the most highly pathogenic viruses against humans, including SARS-CoV-2, MERS-CoV, and SARS-CoV Khan et al. (2020), Cui et al. (2019)

\section{CORONA VIRUS STRUCTURE}

The characteristic morphology of Corona virus is spherical envelope, with clubshaped projections, that look like solar corona or a crown and made of a highly glycosylated protein called spike protein. It has other three structural proteins, envelope, membrane, and nucleocapsid. The virus genome is single strand positivesense RNA, that is similar to host mRNA of approximately (26 to 32) kb. The first two-thirds of the genome consists of two large overlapping open reading frames that encode sixteen (16) nonstructural proteins, including proteases, RNAdependent RNA polymerase (prRdRp), RNA helicase, primase, and others, that form the viral replicase complex, a platform to propagate viral mRNAs. The remaining portion of the genome includes interspersed open reading frames for the structural proteins, as well as a number of accessory proteins generally nonessential for replication in tissue culture but capable of suppressing immune responses and enhancing pathogenesis. The nonstructural proteins are all potential targets for therapies, which would in theory work against all corona viruses. Bergmann and Silverman (2020).

Symptoms of COVID-19 starts from two days to two weeks after exposure to the virus with mean incubation period of about five (5) days WHO (2020). Presentations of COVID-19 have ranged from asymptomatic, mild symptoms, to severe illness and death. Common symptoms have included fever, cough, and shortness of breath. Other symptoms, such as malaise and respiratory distress, have also been described Lauer et al. (2020), Hui et al. (2020).

Viral genome replication is essential step in the virus life cycle and it is a potential site for antiviral intervention, such as chain terminators and other antiviral drugs acting by inhibiting different steps in the virus life cycle.

The development of effective intervention strategies relies on the knowledge of molecular and cellular mechanisms of corona virus infections, there is urgent need to understand why SARS- CoV-2, in contrast to SARS- $\mathrm{CoV}$, is replicating so efficiently in the upper respiratory tract and which viral and host determinants are decisive on whether COVID-19 patients will develop mild or severe disease. Philip V'kovski et al. (2021)

The unprecedented serious challenge of emergence of HIV virus and AIDS in the precious century has proved that new medicines to tackle the emerging disease can be developed. Azidothymidine (Zidovudine or AZT), which inhibit viral replicase proteins, is used for the treatment of HIV-type1and 2, and most of the early antiviral drugs, such as acyclovir, were nucleoside and nucleotide analogues, Julia et al. (2005)

\section{COVID-19; PROMISING REPLICATING INHIBITORS}

SARS-CoV-2 replication is associated with a down regulation of host cell protease inhibitors. The protease inhibitor aprotinin inhibited SARS-CoV-2 replication in therapeutically achievable concentrations. Therapeutic aprotinin concentrations exert anti-SARS-CoV-2 activity. Aprotinin is a serine protease inhibitor, which has been shown to inhibit transmembrane serine protease 2 (TMPRSS2) and has been suggested as optional treatment for influenza and corona viruses. Aprotinin aerosol may have potential for the early local control of SARS- 
CoV-2 replication and the prevention of COVID-19 progression to a severe, systemic disease. Bojkova et al (2020).

Due to the urgent need to control COVID -19 infection pandemic, use of existing antiviral drugs with showed potential inhibiting effects on the replication of coronavirus has been adopted as optional therapeutic tools. Nelfinavir has previously demonstrated antiretroviral activity and used as drug against HIV- type 1. It inhibits the replication of the SARS and SARS-CoV-2-in vitro. It showed potential inhibition against the viral protease such as 3CLpro Norio et al. (2020).

Nucleotide analog drugs can inhibit the viral replication cycle through targeting the viral RNA-dependent RNA polymerase, essential for transcription and replication of RNA genome, such as Favipiravir, which is a guanine analog with activity against many RNA viruses such as SARS-CoV-2 via inhibition the viral RNAdependent RNA polymerase. It acts as chain terminator. Other drug is Ribavirin and galidesivir, the originally antiviral drugs against the HCV, are able to bind to the RNA-dependent RNA polymerase of SARS-CoV-2 and inhibit the viral RNA synthesis.

Ivermectin is an FDA-approved broad spectrum anti-parasitic agent. Reports suggested that ivermectin's nuclear transport inhibitory activity may be effective against SARS-CoV-2 Leon et al. (2020)

Lumacaftor and Cepharanthine displayed activity in inhibiting helicase Nsp13 ATPase activity of SARS-CoV-2, essential for viral replication and the most conserved nonstructural protein within the corona virus family, promising that these drugs can be potentially considered for the treatment of COVID-19 Mark et al. (2020). All of these drugs are potential candidates to be evaluated in clinical trials and repurposed for treatment of COVID-19.

\section{REMDESIVIR (RDV)}

The most promising drug is Remdesivir (RDV), monophosphoramidate prodrug with a molecular mass of $602.6 \mathrm{~g} / \mathrm{mol}$ and chemical formula C27H35N608P. It is known as GS-5734, and metabolized into GS-441524, Frediansyaha et al. (2021). It is an adenosine analog, a primary developed drug by Gilead Sciences of Foster City, California, US. in 2017 to treat the Ebola, and has a potential activity against a wide spectrum of single stranded RNA viruses such as SARS-CoV-2, which acts as an RNA-dependent RNA polymerase inhibitor by binding to the viral RNA-dependent RNA polymerase, and hence, it is an RNA-chain terminator. It is effective as dose of $(10 \mathrm{mg} / \mathrm{kg})$ for twelve (12) days and it is safety in the human is demonstrated by clinical trials. Ghanbari et al. (2020), Yousefi et al. (2020).

Remdesivir was found to be superior to placebo in shortening the time to recovery in adults who were hospitalized with COVID-19 and had evidence of lowering respiratory tract infection, as suggested by the results of multi- national clinical trial John et al (2020),ClinicalTrials.gov Identifier NCT04292730 (2021), ClinicalTrials.gov Identifier: NCT04292899 (2020)).

Supported by data from multiple clinical trials, Remdesivir (Veklury) is the first authorized medicine by the European Medicine Agency (EMA) for SARS-COV2 treatment on June 25/2020 EMA (2020). It is also the first drug to win full U.S. Food and Drug Administration (FDA) approval for treating COVID-19, in adult and pediatric patients twelve (12) years of age and older and weighing at least forty (40) kilograms, on October 22/ 2020.Remdesivir should only be administered in healthcare settings capable of providing acute care similar to inpatient hospital care FDA (2020). The adverse reactions known after receiving Remdesivir include 
gastrointestinal disturbances such as nausea and vomiting, hepatoxicity with elevations of liver enzyme aminotransferase, and infusion related reaction, such as hypotension, and shivering Lam et al. (2020).

\section{MOLNUPIRAVIR; THE EXPECTED GAME CHANGER}

It is known as (82) Merck bills, a nucleoside analogue, the first oral antiviral treatment for COVID -19 reporting promising clinical trial data. It is developed by Merck- US drug- maker company. It is originally used to treat influenza. It is designed to introduce errors into the genetic code of the virus, when incorporated into viral RNA, shifting its configuration, mimicking the nucleoside cytidine and uridine, causing point mutation, and where deleterious transition mutations accumulate in viral RNA causing lethal mutagenesis, which eventually leading to viral population collapse. Malone and Elizabeth (2021).

Campbell. Trial results suggest molnupiravir needs to be taken early after symptoms develop to have an effect. It can cut hospitalizations and deaths among people with COVID-19 by half (50\%). The possibility that molnupiravir could incorporate itself into human DNA, raise safety concerns and need to be monitored Fischer et al. (2021), Sheahan et al. (2020) Cox et al. (2021).

Molnupiravir has been approved in United Kingdom by Medicines and Healthcare Products Regulatory Agency for the treatment of established infections of COVID-19, in November 2021. Mahase (2021). On Friday19 th 2021 EMA. (2020) ;the European Medicines Agency, which is the European Union's drug regulator, approved emergency use of (Molnupiravir) Merck's COVID pills for adults who have tested positive for COVID-19 and it prepares to make a decision on full approval by the end of the year.

Molnupiravir along with vaccination, will reduce dramatically the burden on the health systems globally, and speed up the ending of the COVID-19 pandemic.

\section{PAXLOVID; ANOTHER REAL GAME-CHANGER}

Paxlovid oral bills, developed by Pfizer; US pharmaceutical company contain two components: PF-07321332 and ritonavir. PF-07321332 is protease inhibitor, blocking 3CL protease ; 3C-like protease, an endopeptidase, is the main cysteine protease found in coronaviruses. It cleaves the virus polyprotein at eleven conserved sites. 3CL protease inhibitors prevent viral replication by selectively binding to viral proteases and blocking proteolytic cleavage of protein precursors that are necessary for the production of infectious viral particles. Protease inhibitors have been used for the treatment of HIV and hepatitis C. Ritonavir prevents cytochrome enzymes from destroying PF-07321332. Ritonavir plays the same defensive role in antiviral drug cocktails for HIV treatment. Paxlovid oral bills are given every twelve (12). hours for five days.It reduces the risk of hospitalization by eighty nine percent ( $89 \%$ ). Less than one percent $(1 \%)$ of patients taking the drug needed to be hospitalized and no death reported in the active group compared to seven percent (7\%) hospitalization and ten (10) death, which was about $(1.6 \%)$ in the placebo group, out of seven hundred and seventy-five (775) adult participant in the clinical trial, as the company announced that on Friday, $5^{\text {th }}$ of November, 2021.It is obviously more effective than Molnupiravir of Merck Company. The side effects

of the drugs were mild and reported in about nineteen percent (19\%) versus twenty one percent (21\%) in the placebo group. Mahase (2021). The Molnupiravir and Paxlovid are expected to be approved and available for COVID-19 patients in most countries before the end of this year 2021. 
The challenge faces antiviral therapy is the unpleasant side effects, as well as financial cost. There is urgent need to develop more safe, tolerable and efficacious drugs, with lesser side effects Julia et al. (2005).

\section{DISCLAIMER}

The information in this review should not be used for diagnosis and treatment of individuals' problems or in place of a consultation with competent health care professionals.

The author and publisher disclaim all responsibility for any errors or harms occur as the results obtained from use of the information contained in this review.

\section{AUTHOR CONTRIBUTIONS}

All authors have contributed significantly to conceptualization of the idea, writing the original draft preparation reviewing and editing. All authors have read and agreed to the published version of the manuscript.

\section{CONFLICTS OF INTEREST}

All authors have no conflicts of interest to declare. All authors have no relevant affiliations or financial involvement with any organization or entity with a financial interest in or conflict with the subject matter or materials discussed in the manuscript.

\section{ABBREVIATIONS}

DNA; Dexoyribonucleic Acid, RNA; Ribonucleic Acid. EMA; European medicine Agency. EUA; Emergency Use Authorization. FAD; Food and Drugs Administration, CDC; Centers for Disease Control and Prevention. Kb; Kilo base.

\section{REFERENCES}

Andri Frediansyaha, Ruchi Tiwari, Khan Sharund, Kuldeep Dhamae, and Harapan Harapan. (2021) Antivirals for COVID-19: A critical review. Clinical Epidemiology and Global Health. 9: 90-98. Retrieved from https://doi.org/10.1016/j.cegh.2020.07.006

Bahman Yousefi , Saeid Valizadeh, Hadi Ghaffari, Azadeh Vahedi ,Mohsen Karbalaei, and Majid Eslami. (2020).A global treatments for coronaviruses including COVID-19J Cell Physiol.;235:9133-9142. Retrieved from https://doi.org/10.1002/jcp.29785

Bergmann and Silverman. (2020) .COVID-19: Coronavirus replication, pathogenesis, and therapeutic strategies. Cleveland Clinic Journal of Medicine ; Volume 87 . Number 6 . Retrieved from https://doi.org/10.3949/ccjm.87a.20047

Brandon Malone and Elizabeth A. (2021) Campbell. Molnupiravir: coding for catastrophe. Nature Structural \& Molecular Biology | VOL 28 | SepTeMbeR 2021 | 706-711 | www.nature.com/nsmb. Retrieved from https://doi.org/10.1038/s41594-021-00657-8

ClinicalTrials.gov Identifier NCT04292730 : (2021). A Phase 3 Randomized Study to Evaluate the Safety and Antiviral Activity of Remdesivir (GS-5734 ${ }^{\mathrm{TM}}$ ) in Participants With Moderate COVID-19 Compared to Standard of Care Treatment.. Last Update Posted : January 26, 2021. 
ClinicalTrials.gov Identifier: NCT04292899 . (2020).A Phase 3 Randomized Study to Evaluate the Safety and Antiviral Activity of Remdesivir (GS-5734 ${ }^{\mathrm{TM}}$ ) in Participants With Severe COVID-19. Last Update Posted : December 31, 2020

Cox, R. M. et al. (2021).Therapeutically administered ribonucleoside analogue MK4482/EIDD-2801 blocks SARS-CoV-2 transmission in ferrets Nature Microbiol. 6, 11-18 . Retrieved from https://doi.org/10.1038/s41564-02000835-2

Cui J, Li F, Shi ZL. (2019). Origin and evolution of pathogenic coronaviruses. Nat Rev Microbiol 17:181-192. Retrieved from https://doi.org/10.1038/s41579018-0118-9

Denisa Bojkova, Marco Bechtel, Katie-May McLaughlin, et al (2020).Aprotinin Inhibits SARS-CoV-2 Replication. Cells, 9, 2377. Retrieved from https://doi.org/10.3390/cells9112377

EMA. (2020). European Medicine Agency (EMA).First COVID-19 treatment recommended for EU authorization. Press release 25/06/2020

Elisabeth Mahase. (2021)b. Covid-19: Pfizer 's paxlovid is $89 \%$ effective in patients at risk of serious illness, company reports. BMJ 2021;375:n2713. Retrieved from https://doi.org/10.1136/bmj.n2713

Elisabeth Mahase (2021). b.. Covid-19: UK becomes first country to authorise antiviral molnupiravir. BMJ 2021;375:n2697. Retrieved from https://doi.org/10.1136/bmj.n2697

FDA. (2020). FDA News Release. FDA Approves First Treatment for COVID-19. October 22, 2020. Retrieved from https://doi.org/10.1002/cpu.30542

HarapanHarapan. Naoya Itoh. (2020) Coronavirus disease 2019 (COVID-19): A literature review. J Infect Public Health.; 13(5): 667-673. Retrieved from https://doi.org/10.1016/j.jiph.2020.03.019

Hui DS, I Azhar E, Madani TA, Ntoumi F, Kock R, Dar O, et al. ( 2020) The continuing 2019-nCoV epidemic threat of novel coronaviruses to global health - The latest 2019 novel coronavirus outbreak in Wuhan, China. Int J Infect Dis.. 91:264-266. Retrieved from https://doi.org/10.1016/j.ijid.2020.01.009

John H. Beigel, Kay M. Tomashek, Lori E. Dodd, Aneesh K. Mehta, Barry S. Zingman, Andre C. Kalil, Elizabeth Hohmann, Helen Y. Chu, Annie Luetkemeyer, Susan Kline, Diego Lopez de Castilla, Robert W. Finberg, et al (2020). For the ACTT1 Study Group Members..Remdesivir for the Treatment of Covid-19 - Final Report .N Engl J Med; 383:1813-1826. Retrieved from https://doi.org/10.1056/NEJMoa2007764

Julia Magden, Leevi Kääriäinen, and Tero Ahola. (2005). Inhibitors of virus replication: recent developments and prospects .Appl Microbiol Biotechnol. 66(6): 612-621. Retrieved from https://doi.org/10.1007/s00253-0041783-3

Lauer SA, Grantz KH, Bi Q, Jones FK, Zheng Q, Meredith HR, et al. (2020) The Incubation Period of Coronavirus Disease 2019 (COVID-19) From Publicly Reported Confirmed Cases: Estimation and Application. Ann Intern Med. Retrieved from https://doi.org/10.1101/2020.02.02.20020016

Leon Calya, Julian D. Drucea, Mike G. Cattona, David A. Jans, Kylie M. Wagstaffb. (2020). The FDA-approved drug ivermectin inhibits the replication of SARSCoV-2 in vitro. Antiviral Research 178 ; 104787. Retrieved from https://doi.org/10.1016/j.antiviral.2020.104787 
Mark Andrew White, Wei Lin, and Xiaodong Cheng. (2020). Discovery of COVID-19 Inhibitors Targeting the SARS-CoV-2 Nsp13 Helicase . J. Phys. Chem. Lett. 11, 9144-9151. Retrieved from https://doi.org/10.1021/acs.jpclett.0c02421

Norio Yamamoto, Shutoku Matsuyama, Tyuji Hoshino, and Naoki Yamamoto. (2020). Nelfinavir inhibits replication of severe acute respiratory syndrome coronavirus 2 in vitro. BioRxiv preprint. Retrieved from https://doi.org/10.1101/2020.04.06.026476

Philip V'kovski, Annika Kratzel, Silvio Steiner, Hanspeter Stalder and Volker Thiel (2021). Coronavirus biology and replication: implications for SARS- CoV2.Nature Reviews Microbiology volume 19 .157. Retrieved from https://doi.org/10.1038/s41579-020-00468-6

Reza Ghanbari, Ali Teimoori, Anahita Sadeghi, Ashraf Mohamadkhani, Sama Rezasoltani, Ebrahim Asadi, Abolghasem Jouyban \& Susan CJ Sumner. (2020). Existing antiviral options against SARS-CoV-2 replication in COVID19 patients. Future Microbiol. 15(18), 1747-1758. Retrieved from https://doi.org/10.2217/fmb-2020-0120

Sarah Lam, Andrew Lombardi, and Aviv Ouanounou. (2020) COVID-19: A review of the proposed pharmacological treatments. Eur J Pharmacol.; 886: 173451. Retrieved from https://doi.org/10.1016/j.ejphar.2020.173451

Schoeman, D., Fielding, B.C. (2019). Coronavirus envelope protein: current knowledge. Virol J ; 16, 69. Retrieved from https://doi.org/10.1186/s12985-019-1182-0

Sheahan, T. P. et al. (2020). An orally bioavailable broad-spectrum antiviral inhibits SARS-CoV-2 in human airway epithelial cell cultures and multiple coronaviruses in mice Sci. Transl. Med. 12. Retrieved from https://doi.org/10.1126/scitranslmed.abb5883

Subramanian Boopathi. Adolfo B Poma. PonmalaiKolandaivel (2020) Novel 2019 Coronavirus Structure, Mechanism of Action, Antiviral Drug Promises and Rule Out Against Its Treatment. J BiomolStruct Dyn;1-10. Retrieved from https://doi.org/10.1080/07391102.2020.1758788

Suliman Khan. Rabeea Siddique. Muhammad Adnan Shereen. Ashaq Ali. Jianbo Liu. Qian Bai. Nadia Bashir. and MengzhouXue. (2020) Emergence of a Novel Coronavirus, Severe Acute Respiratory Syndrome Coronavirus 2: Biology and Therapeutic Options. J Clin Microbiol.; 58(5): e00187-20. Retrieved from https://doi.org/10.1128/JCM.00187-20

WHO (2020). Retrieved from https://covid19.who.int/

William Fischer, Joseph J. Eron, Wayne Holman, Myron S. Cohen, et al. (2021) Molnupiravir, an Oral Antiviral Treatment for COVID-19. Version 1. medRxiv. Preprint. Retrieved from https://doi.org/10.1101/2021.06.17.21258639 